\title{
Characteristics of Nursing Care for Terminally Ill Patients in Hospice/Palliative Care Unit
}

\author{
Kaori Tsutsumi ${ }^{1}$, Keiko Sekido² ${ }^{2}$, Tetsuya Tanioka ${ }^{3}$ \\ ${ }^{1}$ Department of Nursing, Tsukuba International University, Ibaraki, Japan \\ ${ }^{2}$ Department of Nursing, Kobe University Graduate School of Health Sciences, Kobe, Japan \\ ${ }^{3}$ Department of Nursing, Institute of Health Biosciences, The University of Tokushima Graduate School, \\ Tokushima, Japan \\ Email: k-tsutsumi@tius.ac.jp
}

Received 4 July 2014; revised 21 August 2014; accepted 4 September 2014

Copyright (C) 2014 by authors and Scientific Research Publishing Inc.

This work is licensed under the Creative Commons Attribution International License (CC BY). http://creativecommons.org/licenses/by/4.0/

c)

\section{Abstract}

The purpose of this study was to clarify the characteristics of nursing care for patient with terminally ill in the hospice/palliative care units. Semi-structured interviews on "communication, care, spiritual pain care and prediction of worsening of symptoms" were conducted, incorporating items indicated as important principles of palliative care by Lugton et al. Sixteen nurses at five hospice/ palliative care facilities in urban areas of Japan were surveyed in 2013 , and results were analyzed qualitatively. Following characteristics by hospice/palliative care nurses (HPN) were categorized as [HPN sharing meaningful time with the patient] and [HPN's continual attempts to understand the world in which the patient lives] in the communication; as [HPN providing comfortable care so that patients can value their last moments] and [HPN's efforts to attend to patients so they can die as they hope to] in the care; and as [HPN's observation in a range that does not interfere with the patient's comfort] and [HPN senses that something is different from before] in the prediction of worsening of symptoms. Common characteristic was <HPN's support for patients approaching a natural death>. In this study, spiritual pain care was included in the communication and care, and could not be extracted alone. It was suggested that an HPN provides communication, care and prediction of worsening of symptoms with excellent judgment and technological competency, while placing importance on offering support for the patient's natural death.

\section{Keywords}

Hospice/Palliative Care Nurse, Nursing Care for Patient with Terminally Ill 


\section{Introduction}

There are a wide variety of problems in nursing care for patients with terminally ill. In care, communication is important in the patient-nurse relationship [1], and particularly at the end of life, effective caring is not possible without communication [2] [3]. Patients and their families express frustration with [4] lack of communication between terminally ill patients and nurses [5] [6], but evidence on improvement of communication, provides future communication skills training to advance hospice clinicians’ interactions with patients and families [7].

Previous study on a "good death" for terminally ill patients [8], families and health care providers [9] [10] have suggested the importance of care to support the process of the patient's "good death". So far, a certain view on the role of nursing for dying people has been shown [11]. Hospices provide higher quality medical care and nursing than general hospitals according to some surveys of families [12]. However, Tu and Chiou suggested that the awareness of others towards the pain and quality of life of terminally patients is low [13]. Little is known about the characteristics of such nursing situation. Therefore, clarifying the characteristics of nursing contributes to accumulation of practical knowledge, and is also important for increasing the expertise of hospice/ palliative nursing care.

The purpose of this study was to clarify the characteristics of nursing care for patient with terminally ill in hospice/palliative care units.

\section{Methods}

\subsection{Study Design}

This study used qualitative descriptive research design. Items indicated by Lugton et al. [11] as important principles of palliative care were employed, and the four items of communication, care, spiritual pain care, and prediction of worsening of symptoms were used as the study's frameworks.

\subsection{Definitions of Terms}

The definition of terminally ill used in this study was "the status of a person who cannot be cured, even with the application of multidisciplinary treatment, and aggressive treatment is rather considered to be inappropriate for the patient. Life prognosis is usually considered to be 6 months or less [14]”.

\subsection{Data Collection}

In response to the explorative study aims, we used a purposive participant selection. We recruited nurses (HPN) who haven't received special training in order to search for the feature of everyday nursing practice in hospice/ palliative care units, through a chief nurse. The participants of the study were 16 HPNs. They were women of age 20 to 40 years with an average of $12.2 \pm 5.4$ years of clinical experience as a nurse, and an average of $4.1 \pm 2.9$ years of clinical experience in hospice/palliative care. The average length of the interview was $32.4 \pm 5.2$ minutes.

Semi-structured interviews were conducted by one researcher. Individual interviews were conducted in Japanese language using the following interview guiding questions:

- What do you do that is important for communication with a terminally ill patient?

- What important care do you perform?

- What kind of spiritual pain care do you perform?

- From what do you predict worsening of symptoms?

Interviews were held in a place where privacy could be secured, such as a meeting room. Content of the interview was recorded with an IC recorder with the participants' consent, and a verbatim record was prepared. Data collection was done from June to August 2013.

\subsection{Data Analysis}

The data was approached in an interactive process. Data analysis started early in the data collection process. The authors regularly shared experiences and this constituted a basis for individual and joint reflection and discussion. We performed a qualitative content analysis of the data based upon themes emerging from the texts, relevant theories, and earlier research. After reading through the interviews several times to get a sense of meaning, and discussing our preliminary analyses, we saw that the characteristics of nursing care for patient with termi- 
nally ill in hospice/palliative care units. Further discussions of meaning were had before all interviews were analyzed according to a list of themes.

The verbatim records were carefully read, summarized by keeping the context in mind so as not to lose meaning, and coded. The codes were placed in subcategories according to similarity, and the abstraction level was raised in categories.

This study received guidance from an expert in qualitative research throughout all processes, and the rigor of the study was secured. In addition, advice was received from three certified HPN of a cooperating facility to check for any misinterpretation of the analytic results, in an effort to assure the validity of the analytic results.

\subsection{Ethical Considerations}

In requesting the study, the gist of the research was first explained to the nursing director and chief ward HPN. Upon obtaining their consent, the participants were introduced to us. The voluntary nature of participation in the study and freedom to withdraw, the advantages and disadvantages of participation in the survey, protection of personal information, publication of research results and handling before and after the study were explained to the participants orally and in writing, and signed consent was obtained. This study was conducted with approval (No. 222) of the Kobe University Graduate School of Health Sciences Ethics Committee.

\section{Results}

Spiritual pain care was included in communication and care. Therefore, characteristics other than spiritual pain care were shown in Table 1 in this study. Categories are shown in $<>$, sub-categories in [ ], and open codes in $\{$ \}below. The narrative central to the category was shown in italics.

\subsection{Characteristics of Communication}

One category was extracted as a characteristic of HPN communication: <Communication by HPN to support patients approaching a natural death $>$. This was composed of two sub-categories.

1) [HPN sharing meaningful time with the patient] was composed of eight open codes: $\{H P N$ creates a place where patients can talk about what they want to\}; \{HPN intentionally makes time to be together with patients\}; \{HPN gauges the pace and timing at which a patient wants to talk\}; $\{\mathrm{HPN}$ has a sense of proper distance from the patient, not too close or far\}; \{HPN sits and listens to patients carefully with eye contact $\}$; $\{$ HPN listens to patients patiently without interrupting, even if it takes time $\}$; $\{$ HPN listens to patients with an open mind, without being skeptical $\}$; and $\{$ HPN shares time with patients in silence $\}$.

"Whenever I talk with a patient, however busy or rushed I am, I sit and make eye contact, and listen without interrupting to what the patient wants to say. There are often times just looking at the patient while waiting for the patient to speak, restraining myself even if I have something to say."

"It was difficult before because I couldn't judge what would be a good distance from the patient. Now I can maintain a good sense of distance while matching the timing and pace of the patient's speaking."

"Sometimes both of us are silent. This is nothing to be afraid of, because it is important time with the patient."

2) [HPN's continual attempts to know the world in which the patient lives] was composed of two open codes: \{HPN tries to know the patient's suffering and pain\} and \{HPN builds up relationships with patients\}.

“There are many people here in the hospital who can't let go of life, and are bitter wondering why they must suffer, when they've tried so hard. Some people also suffer from the pain of symptoms. I want to know such patient's pain and suffering up to the end. I think it's important to continue trying to know the patient. So naturally I come to know the patient and family well."

\subsection{Characteristics of Care}

One category was extracted for characteristics of care: <Care by HPN to support patients approaching a natural death>. This was composed of two sub-categories.

1) [HPN providing comfortable care so that patients can value their last moments] was composed of six open codes: $\{$ HPN matches care to the condition and wishes of the patient $\}$; $\{\mathrm{HPN}$ tries to fulfill a patient's modest wishes $\}$; $\{$ HPN provides the best possible care $\}$; $\{\mathrm{HPN}$ judges the need for medical treatment from the suffering 
Table 1. The characteristics of nursing care of hospice/palliative care nurses.

\begin{tabular}{|c|c|c|}
\hline Category & Sub-categories & Open Codes* \\
\hline \multirow[t]{2}{*}{$\begin{array}{l}\text { 1) Communication } \\
\text { by HPN to support } \\
\text { patients approaching } \\
\text { a natural death }\end{array}$} & $\begin{array}{l}\text { HPN sharing meaningful } \\
\text { time with the patient }\end{array}$ & $\begin{array}{l}\cdot \text { creates a place where patients can talk about what they want to } \\
\text { - intentionally makes time to be to get her with patients } \\
\text { - gauges the pace and timing at which a patient wants to talk } \\
\text { - haves a sense of proper distance from the patient, not too close or far } \\
\cdot \text { sits and listens to patients carefully with eye contact } \\
\cdot \text { - listens to patients patiently without interrupting, even if it takes time } \\
\text { - listens to patients with an open mind, without being skeptical } \\
\cdot \text { shares time with patients in silence }\end{array}$ \\
\hline & $\begin{array}{l}\text { HPN's continual attempts } \\
\text { to know the world in } \\
\text { which the patient lives }\end{array}$ & $\begin{array}{l}\text { •tries to know the patient's suffering and pain } \\
\text { •builds up relationships with patients }\end{array}$ \\
\hline \multirow[t]{2}{*}{$\begin{array}{l}\text { 2) Care by HPN } \\
\text { to support patients } \\
\text { approaching } \\
\text { a natural death }\end{array}$} & $\begin{array}{l}\text { HPN providing comfortable } \\
\text { care so that patients can } \\
\text { value their last moments }\end{array}$ & $\begin{array}{l}\cdot \text { matches care to the condition and wishes of the patient } \\
\text { - tries to fulfill a patient's modest wishes } \\
\text { - provides the best possible care } \\
\cdot \text { judges the need for medical treatment from the suffering of the patient } \\
\text { - tries to have the patient spend quality time with the family } \\
\text { - cooperates with staff to provide better care }\end{array}$ \\
\hline & $\begin{array}{l}\text { HPN's efforts to } \\
\text { attend to patients } \\
\text { so they can die as they hope to }\end{array}$ & $\begin{array}{l}\text {-accepts the patients dying as they hope to } \\
\text { • wants to give care that enables the patient to meet the end they hope for }\end{array}$ \\
\hline \multirow{2}{*}{$\begin{array}{l}\text { 3) Predicting } \\
\text { worsening } \\
\text { of symptoms in } \\
\text { a patient } \\
\text { approaching } \\
\text { natural death }\end{array}$} & $\begin{array}{l}\text { HPN observation in a range } \\
\text { that does not interfere with } \\
\text { the patient's comfort }\end{array}$ & $\begin{array}{l}\text { - checks the patient's temperature, pulse, respiration and reflexes } \\
\text { by directly touching the patient's body } \\
\text { - chooses measuring methods with the least burden according to the patient's condition } \\
\text { • is sensitive to day-to-day changes }\end{array}$ \\
\hline & $\begin{array}{l}\text { HPN's sense that something } \\
\text { is different from before }\end{array}$ & $\begin{array}{l}\text { - senses something is different overall from the patient than before } \\
\text { - The family notices a lack of vitality } \\
\text { • senses that the time of death is near }\end{array}$ \\
\hline
\end{tabular}

Notes: The extracted categories from 1) to 3) corresponds with three of four items indicated by Lugton et al. [11]: 1) communication, 2) care, and 3) prediction of worsening of symptoms. ${ }^{*}$ The subject of text without the subject in open codes is hospice/palliative care nurses (HPN).

of the patient\}; $\{$ HPN tries to have the patient spend quality time with the family\}; and $\{$ HPN cooperates with staff to provide better care $\}$.

"Working in the palliative care unit means seeing the death of many patients. It is difficult, and I still often cry. But since I am giving the best care for the patient's condition and needs, there isn't much regret or fear, even knowing that that person will die."

"For example, if the patient's oxygen saturation is low, it's not necessary to begin oxygen supply immediately. The need for oxygen is judged from the person's level of suffering. I think to provide care so that the patient can value the last moments. That is nothing special, just respectfully assisting with daily activities, and accommodating the patient's condition and modest desires. The staff often talk with each other to discuss what to do to provide good care." 
2) [HPN's efforts to attend to patients so they can die as they hope to] was composed of two open codes: $\{$ HPN accepts the patients dying as they hope to $\}$ and $\{$ HPN wants to give care that enables the patient to meet the end they hope for\}.

"In my contact with the patients, I want to give care that enables the patient to meet the end they hope for, with the feelings of being glad to be involved at the important time of end of the patient's life, to be able to be with the person when he/she died, and glad to have met him/her."

\subsection{Characteristics of Predicting Worsening of Symptoms}

One category was extracted for characteristics of predicting worsening of symptoms: <HPN predicts worsening of symptoms in a patient approaching natural death>. This was composed of two sub-categories.

1) [HPN observation in a range that does not interfere with the patient's comfort] was composed of three open codes: $\{$ HPN checks the patient's temperature, pulse, respiration and reflexes by directly touching the patient's body $\} ;$ \{HPN chooses measuring methods with the least burden according to the patient's condition $\}$; and $\{\mathrm{HPN}$ is sensitive to day-to-day changes\}.

"Of course I look at objective data such as blood pressure or test data, but I judge the patient's condition by touching the pulse of the patient's body. Without monitors, I make sure to touch the patient's body and observe carefully to sensitively check daily progress. I consider what the vital measurements are for, and observe to try to ease the patient's pain and burden."

2) [HPN sense that something is different from before] was composed of three open codes: $\{$ HPN senses something is different overall from the patient than before\}; \{The family notices a lack of vitality\}; and $\{\mathrm{HPN}$ senses that the time of death is near\}.

"As the time of death nears, the manner of speaking is different, the expression is dull, and I feel that the person's appearance and atmosphere are somehow different. The family close to the patient may first notice a lack of vitality."

\section{Discussion}

\subsection{Characteristics of Communication}

[HPN sharing meaningful time with the patient] represents the times patients speak what they want to say, as well times they do not speak. Appreciating and sharing time with the patient is not simply the length of time between the HPN and patient, but everything that occurs between them should be valued. This is the behavior of a HPN who wants to be with the patient [3] [5] [15] [16].

In the [HPN's continual attempts to know the world in which the patient lives], the world in which the patient lives is individual experience including all of the feelings that are obtained from being alive [16], and can be called that person's own world. Consequently, no matter how an HPN tries, the patient's world can never be completely understood. For this reason the HPN needs to make continual attempts to know the patient until the patient's last moment. Luker et al. [17] states that it is important for HPN to be involved with patients at an early stage, and to get to know the patients by spending a lot of the time with them. Communication of an HPN with a patient is an attempt to know the patient, which leads to active ties according to Morse et al. [1], with HPN identifying themselves with patients' lived experiences, an involvement which can be called the essence of nursing.

\subsection{Characteristics of Care}

In [HPN providing comfortable care so that patients can value their last moments], comfortable care means the HPN endeavoring to respectfully assisting in daily activities, and matching the condition and needs of the patient to avoid pain. Releasing the patient from suffering of body and mind even for a short time, to be able to value the limited time, is considered the provision of comfortable care by an HPN. Comfort for terminally ill patients is the sense of letting them feel alive, and whether comfort can be provided as care is important in nursing [18]-[20].

While HPNs try to know the patient's world through repeated communication every day, HPNs cooperate with staff aiming to improve care. A team approach is an important characteristic of palliative care [21], and 
sharing information of the patient/family and the direction of nursing leads to better care for both patients and HPN [22].

[HPN's efforts to attend to patients so they can die as they hope to] means the HPN hopes that patients will be able to meet death in the way they wish to, and that the HPN provides care to the patient to gain an knowing of the patient's death in the way the patient hopes. The patient's life is limited, and possibly many HPNs themselves feel that the process of care is difficult. The thoughts and attitude of HPN toward death affects the activeness of their care for dying people [23]-[26], which also affects the satisfaction of the patient and family with end-of-life care. Therefore, the attitude with which an HPN approaches care is important [27]. The HPNs who were the participants of this survey made efforts to not feel regrets at the death of a patient by giving the best care to the patient and engaging deeply with the patient. Johnston et al. [3] stated that personal characteristics such as kindness and warmth are involved in being an excellent palliative care HPN. However, this study indicated that it is not only an HPN's personal characteristics, but also that the HPN's efforts are involved. HPNs also felt gratitude toward patients for having met them and being involved in their last moments of life. Moreover, HPNs said that they tried to know what kind of death the patient would hope for. These are feelings toward the patient which are obtained by repeated communication and care for the patient day after day, and are rooted in sincere feelings about the person, and are considered to be feelings toward the patient obtained from sincere efforts as an HPN.

\subsection{Characteristics of Predicting Worsening of Symptoms}

Both patients and HPN are aware that various types of pain intensify at the end of life [28], such as breathing difficulties and physical suffering [29] [30]. HPNs predicted the worsening of symptoms by methods without pain or burden to the patient, such as by touching and examining the patient's body, and judging from changes in daily activities, which is to say [HPN's observation in a range that does not interfere with the patient's comfort]. This shows the nursing technique of having a basic knowledge of the natural changes in a person approaching death and preventing the intensification of the pain associated with them, with the judgment to accurately understand the patient's condition.

[HPN sense that something is different from before], at the same time as being an indicator of worsening of symptoms, is an important sense as an indicator for predicting that the time of death is near, and is considered to be an observational power cultivated by experience. It was thought that in this way even a patient's trivial reactions could be detected without overlooking them. In research on clinical judgment of HPN in surgical wards [31], the same type of sense was used. HPNs show an excellent sense for when something is wrong that cannot be put into words, by nursing practice in communication and care of terminally ill patients.

\subsection{Characteristics of Nursing in Hospice/Palliative Care}

Implementation of medical treatment at the end of life can turn out to be counter to a natural human death [32][34]. Therefore, in the terminal phase, a natural death, approaching death without pain as far as possible, is desirable for humans. In this study, it was considered that those were related and affected categories, a common characteristic of nursing care by HPN was extracted as <Support for patients approaching a natural death>. This means that the patient's limited time is a valuable time for both the patient and the HPN, and the HPN tries to be with the patient. This was considered a foundation of HPN nursing practice. Communication with the patient by the HPN, care for the patient, and prediction of worsening of symptoms were practiced with mutual interaction until the patient's death.

Spiritual pain care could not be extracted alone in the study. This is related to the fact that the term "spiritual" and its perception are still unclear in Japan, and there is no consensus even among HPN [35].

\subsection{Limitations of This Study and Future Issues}

This study was an analysis of interviews obtained from sixteen HPNs involved with terminally ill patients, and there is a limit to generalization. In the future, nursing characteristics depending on the stage of the disease of the patient and differences with certified/specialized HPN should be investigated to further clarify the expertise of hospice/palliative care. 


\section{Conclusion}

From interviews with sixteen HPN working in hospice/palliative care units, two sub-categories in the communication, two sub-categories in the care, and two sub-categories in the predicting worsening of symptoms were extracted. These had the common characteristic of HPN's < Support for patients approaching a natural death>. It was suggested that HPNs place importance on support for a natural death, while providing excellent judgment and skills in communication with patients, care for patients, and predicting worsening of patient's symptoms.

\section{Acknowledgements}

The authors would like to thank all of the hospice/palliative care HPN who cooperated with this study, as well as the hospital directors, nursing directors and head HPN.

\section{Disclosure}

All of the coauthors declare that they have no direct conflict of interest or grant support that is directly related to the content of the study.

\section{References}

[1] Morse, J.M., Bottorff, J., Anderson, G., et al. (1992) Beyond Empathy Expanding Expressions of Caring. Journal of Advanced Nursing, 17, 809-821. http://dx.doi.org/10.1111/j.1365-2648.1992.tb02002.x

[2] Byrne, D. and McMurray, A. (1997) Caring for the Dying: Nurses' Experiences in Hospice Care. The Australian Journal of Advanced Nursing, 15, 4-11.

[3] Johnston, B. and Smith, L.N. (2006) Nurses' and Patients’ Perceptions of Expert Palliative Nursing Care. Journal of Advanced Nursing, 54, 700-709. http://dx.doi.org/10.1111/j.1365-2648.2006.03857.x

[4] Finke, E.H., Light, J. and Kitko, L. (2008) A Systematic Review of the Effectiveness of Nurse Communication with Patients with Complex Communication Needs with a Focus on the Use of Augmentative and Alternative Communication. Journal of Clinical Nursing, 17, 2102-2115. http://dx.doi.org/10.1111/j.1365-2702.2008.02373.x

[5] Wilkinson, S. (1991) Factors Which Influence How Nurses Communicate with Cancer Patients. Journal of Advanced Nursing, 16, 677-688. http://dx.doi.org/10.1111/j.1365-2648.1991.tb01726.x

[6] McCabe, C. (2004) Nurse-Patient Communication: An Exploration of Patients' Experiences. Journal of Clinical Nursing, 13, 41-49. http://dx.doi.org/10.1111/j.1365-2702.2004.00817.x

[7] Ellington, L., Reblin, M., Clayton, M.F., et al. (2012) Hospice Nurse Communication with Patients with Cancer and Their Family Caregivers. Journal of Palliative Medicine, 15, 262-268. http://dx.doi.org/10.1089/jpm.2011.0287

[8] Goldsteen, M., Houtepen, R., Proot, I.M., et al. (2006) What Is a Good Death? Terminally Ill Patients Dealing with Normative Expectations around Death and Dying. Patient Education and Counseling, 64, 378-386. http://dx.doi.org/10.1016/j.pec.2006.04.008

[9] Steinhauser, K.E., Clipp, E.C., Mcneilly, M., et al. (2006) In Search of a Good Death: Observations of Patients, Families, and Providers. Annals of Internal Medicine, 132, 825-832. http://dx.doi.org/10.7326/0003-4819-132-10-200005160-00011

[10] Hirai, K., Miyashita, M., Morita, T., et al. (2006) Good Death in Japanese Cancer Care: A Qualitative Study. Journal of Pain and Symptom Management, 31, 140-147. http://dx.doi.org/10.1016/j.jpainsymman.2005.06.012

[11] Lugton, J. and McIntyre, R. (2006) Palliative Care: The Nursing Role. 2nd Edition, Elsevier Churchill Livingstone, London.

[12] Addington-Hall, J.M. and O’Callaghan, A.C. (2009) A Comparison of the Quality of Care Provided to Cancer Patients in the UK in the Last Three Months of Life in In-Patient Hospices Compared with Hospitals, from the Perspective of Bereaved Relatives: Results from a Survey Using the VOICES Questionnaire. Palliative Medicine, 23, 190-197. http://dx.doi.org/10.1177/0269216309102525

[13] Tu, M.S. and Chiou, C.P. (2007) Perceptual Consistency of Pain and Quality of Life between Hospice Cancer Patients and Family Caregivers: A Pilot Study. International Journal of Clinical Practice, 61, 1686-1691. http://dx.doi.org/10.1111/j.1742-1241.2007.01347.x

[14] Nakanishi, M. and Ohishi, M. (2002) Nursing \& Medical Dictionary. 6th Edition, Igaku-shoin, Tokyo, 407-408. (in Japanese)

[15] Sekido, K., Ishikawa, N. and Katagiri, Y. (2000) A Study of Communication Skills of Nursing Students with Terminally Ill Patients (2). Hospice and Home Care, 8, 44-48. (in Japanese) 
[16] Boykin, A. and Schoenhofer, S.O. (1993) Nursing as Caring A Model for Transforming Practice. The Project Gutenberg EBook, 11-22. http://www.gutenberg.org/files/42988/42988-pdf

[17] Luker, K.A., Austin, L., Caress, A. and Hallett, C.E. (2000) The Importance of "Knowing the Patient": Community Nurses’ Constructions of Quality in Providing Palliative Care. Journal of Advanced Nursing, 31, 775-782. http://dx.doi.org/10.1046/j.1365-2648.2000.01364.x

[18] Williams, A.M. and Irurita, V.F. (2005) Enhancing the Therapeutic Potential of Hospital Environments by Increasing the Personal Control and Emotional Comfort of Hospitalized Patients. Applied Nursing Research, 18, 22-28. http://dx.doi.org/10.1016/j.apnr.2004.11.001

[19] Williams, A.M. and Irurita, V.F. (2006) Emotional Comfort: The Patient's Perspective of a Therapeutic Context. International Journal of Nursing Studies, 43, 405-415. http://dx.doi.org/10.1016/j.ijnurstu.2005.06.004

[20] Kim, K.S. and Kwon, S.H. (2007) Comfort and Quality of Life of Cancer Patients. Asian Nursing Research, 1, $125-135$. http://dx.doi.org/10.1016/S1976-1317(08)60015-8

[21] Lowey, S.E. (2008) Communication between the Nurse and Family Caregiver in End-of-Life Care: A Review of the Literature. Journal of Hospice and Palliative Nursing, 10, 35-45. http://dx.doi.org/10.1097/01.NJH.0000306712.65786.ae

[22] Cartwright, J.C., Miller, L. and Volpin, M. (2009) Hospice in Assisted Living: Promoting Good Quality Care at End of Life. Gerontologist, 49, 508-516. http://dx.doi.org/10.1093/geront/gnp038

[23] Dunn, K.S., Otten, C. and Stephena, E. (2005) Nursing Experience and the Care of Dying Patients. Oncology Nursing Forum, 32, 97-104. http://dx.doi.org/10.1188/10.ONF.E43-E49

[24] Lange, M., Thom, B. and Kline, N.E. (2008) Assessing Nurses’ Attitudes toward Death and Caring for Dying Patients in a Comprehensive Cancer Center. Oncology Nursing Forum, 35, 955-959.

[25] Braun, M., Gordon, D. and Uziely, B. (2010) Associations between Oncology Nurses’ Attitudes toward Death and Caring for Dying Patients. Oncology Nursing Forum, 37, E43-E49. http://dx.doi.org/10.1188/10.ONF.E43-E49

[26] Gama, G., Barbosa, F. and Vieira, M. (2012) Factors Influencing Nurses’ Attitudes toward Death. International Journal of Palliative Nursing, 18, 267-273. http://dx.doi.org/10.12968/ijpn.2012.18.6.267

[27] Rolland, R.A. and Kalman, M. (2007) Nurses’ Attitudes about End-of-Life Referrals. Journal of the New York State Nurses Association, 38, 10-12.

[28] Larsson, A. and Wijk, H. (2007) Patient Experiences of Pain and Pain Management at the End of Life: A Pilot Study. Pain Management Nursing, 8, 12-16. http://dx.doi.org/10.1016/j.pmn.2006.12.001

[29] Lo, R.S., Woo, J., Zhoc, K.C., Li, C.Y.P., Yeo, W., Johnson, P., et al. (2002) Quality of Life of Palliative Care Patients in the Last Two Weeks of Life. Journal of Pain and Symptom Management, 24, 388-397. http://dx.doi.org/10.1016/S0885-3924(02)00504-3

[30] Ferrand, E., Jabre, P., Vincent-Genod, C., Aubry, R., Badet, M., Badia, P., et al. (2008) Circumstances of Death in Hospitalized Patients and Nurses' Perceptions French Multicenter Mort-a-l'Hôpital Survey. Archives of Internal Medicine, 168, 867-875. http://dx.doi.org/10.1001/archinte.168.8.867

[31] Sugimura, A. and Ando, S. (2013) Correlation of Dyspnea Management and Knowledge, Skills, and Attitudes of Nurses Working in Palliative Care Unit. Journal of Japanese Society of Cancer Nursing, 27, 52-60. (in Japanese)

[32] Campbell, M.L., Yarandi, H. and Dove-Medows, E. (2013) Oxygen Is Nonbeneficial for Most Patients Who Are Near Death. Journal of Pain and Symptom Management, 45, 517-523. http://dx.doi.org/10.1016/j.jpainsymman.2012.02.012

[33] Clark, D. (2002) Between Hope and Acceptance: The Medicalisation of Dying. BMJ, 324, 905-907. http://dx.doi.org/10.1136/bmj.324.7342.905

[34] Pearce, C.M. and Duffy, A. (2006) Holistic Care. In: Lugton, J. and McIntyre, R., Eds., Palliative Care: The Nursing Role, Elsevier Churchill Livingstone, London, 68-70.

[35] Shida, K. and Watanabe, K. (2006) A Review of the Literature on Spiritual Care and Nurses' Views of Life and Death in Nursing in Japan. Bulletin of School of Health Sciences Faculty of Medicine Niigata University, 8, 95-107. (in Japanese) 
Scientific Research Publishing (SCIRP) is one of the largest Open Access journal publishers. It is currently publishing more than 200 open access, online, peer-reviewed journals covering a wide range of academic disciplines. SCIRP serves the worldwide academic communities and contributes to the progress and application of science with its publication.

Other selected journals from SCIRP are listed as below. Submit your manuscript to us via either submit@scirp.org or Online Submission Portal.
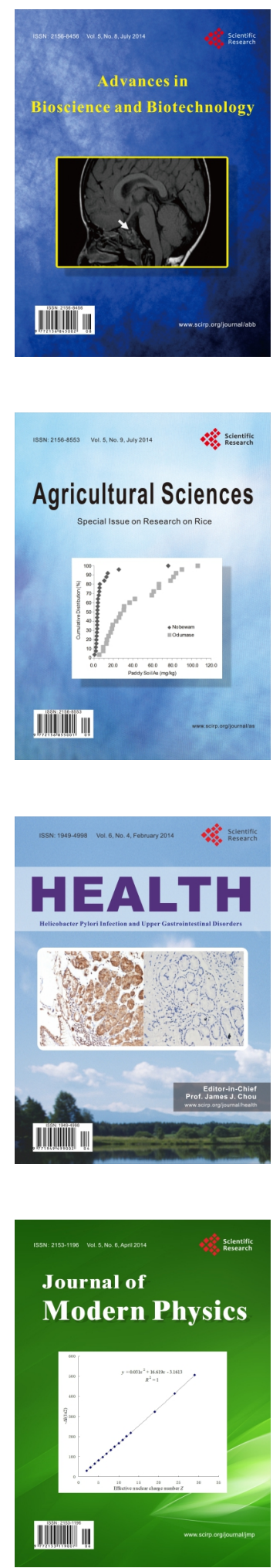
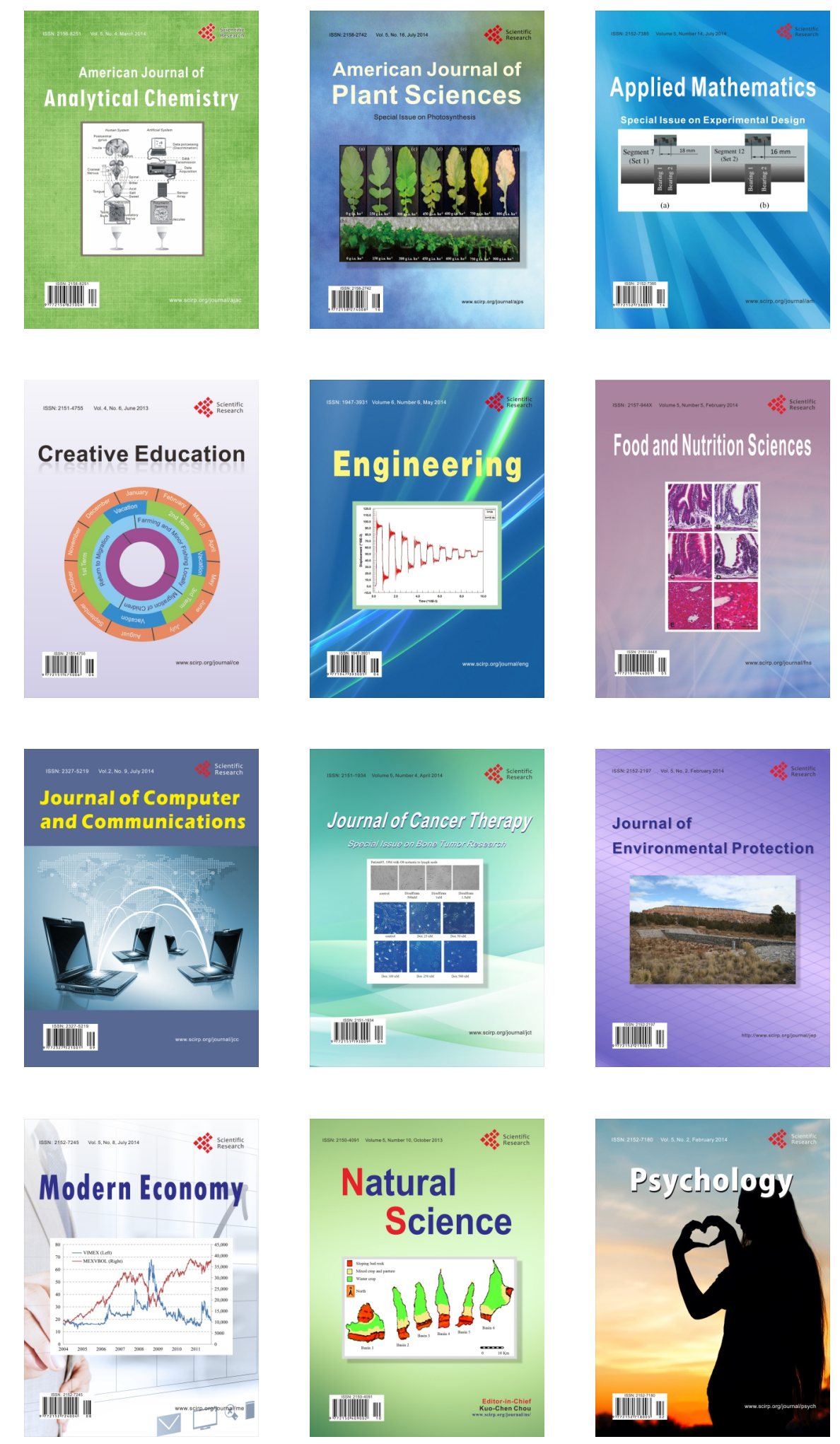